\title{
Thermodynamics of Formation of Porous Polymeric Membrane by Phase Separation Method VI. Supermolecular Structure and Virus Separability of Porous Regenerated Cellulose Membrane Prepared by Phase Separation Method
}

\author{
Hideki Imsma, Kazuko Sogawa, and Kenji Kamide* \\ Fundamental Research Laboratory of Natural and Synthetic Polymers, Asahi Chemical Industry Co., Ltd., \\ 11-7 Hacchonawate, Takatsuki, Osaka 569, Japan \\ * Laboratory of Clothing, Faculty of Education, Kumamoto University. \\ Kurokami 2-40-1, Kumamoto 860, Japan
}

(Received March 29, 1996)

\begin{abstract}
An attempt was made (1) to correlate permeation properties such as filtration rate, filtration coefficient, and critical filtration volume with filtration conditions of virus contaminated aqueous solutions through porous regenerated cellulose membrane, (2) to demonstrate possibility of complete rejection of viruses from filtrate, (3) to clarify the captured state of viruses in the membrane and the concentration distribution of the captured viruses to the direction of thickness of the membrane, and (4) to propose the mechanism of capturing viruses with the membrane by taking into account the membrane structure and a three-dimensional form of pores (i.e., morphology of pores). Porous regenerated cellulose membrane prepared by the phase separation method consisted of the secondary particles of cellulose, and there exist large cavities and narrow veins connecting these cavities in the membrane. Most of virus particles were trapped either in veins by the blocking or in cavities by the accumulation, but a very few of them flowed downstream and finally contaminated in filtrate. A "critical filtration volume $V^{\mathrm{c}}\left[\mathrm{ml} \mathrm{cm}^{-2}\right]$ " was defined as total filtration volume obtained till the moment when the first virus reached to the opposite (i.e., rear) side of the membrane. Complete rejection of viruses from the filtrate was achieved until total filtration volume reached $V^{\mathrm{c}}$, which increased with the pressure difference $\Delta P$ and concentration of virus in the filtrand $c_{0}$. Without exceeding its $V^{\mathrm{c}}$, the porous cellulose membrane will be one of possible membranes designed for the removal of virus from aqueous serum protein mixtures.
\end{abstract}

KEY WORDS Porous Membrane / Cellulose / Virus / Capture / Mechanism / Vacant Pore / Rejection / Critical Filtration Volume /

Based on electron microscopic observation of membranes prepared by phase separation method, Kamide et al. showed that the membranes are constituted of secondary particles of polymer-rich phase (referred to as "polymer particles"), ${ }^{1,2}$ and proposed "three-dimensional thin layers model" of the membrane which consists of polymer particles with radii of $S_{2}$ and hypothetical particles of polymer-lean phase (referred to as "vacant particles"), whose radii are also $S_{2} \cdot{ }^{3}$ Using this model, they established an approximate theory for estimating probability of finding three kinds of pores like through-pores, semi-open pores, and isolated pores in the membrane. ${ }^{3,4}$

In the previous papers, ${ }^{5-9}$ Kamide, Iijima and their collaborators studied more quantitatively the mechanism of membrane structure formation by the phase separation method from view point of "particle growth concept": In case where initial polymer volume fraction $v_{\mathrm{p}}^{0}$ is less than polymer volume fraction at a critical solution point $v_{\mathrm{p}}^{\mathrm{c}}$, they have proposed a theory on the nucleation and growth of nuclei to the primary particles, ${ }^{5}$ and have carried out computer simulation experiments on the growth of the primary particles to the secondary particles. ${ }^{6}$

Furthermore, using a hexagonal lattice plane as a two-dimensional model of thin layers consisting of the membrane, they derived a theory (referred to as "lattice theory") giving pore size distribution $N(r)$ ( $r$, pore radius) and pore density $N_{\mathrm{P}}$ (i.e., number of pores in unit area of membrane) and carried out computer simulation experiments concerning $N(r)$ together with actual experiments on steps of formation of porous structures by contacting the secondary particles. ${ }^{7,8}$ They compared three kinds of pore size distribution: 1$) N(r)$ by an electron microscopic method $N(r)_{\mathrm{EM}}$ of an actual porous cellulose membrane, 2) theoretical $N(r)$ calculated by using average radius of polymer particles on a front surface, membrane porosity estimated by an apparent density method $\operatorname{Pr}\left(\mathrm{d}_{3}\right)$ and degree of contraction $k$ for the actual porous cellulose membrane, and 3) $N(r)$ by computer simulation experiments. By demonstrating reliabilities of both the lattice theory and the membrane model, they examined the proprieties of the membrane. $^{7,8}$

They also established a computer simulation method for constructing a three-dimensional multi-layered structure model of a membrane consisting of polymer particles, and disclosed a three-dimensional shape of through-pores, clarifying relations between an overall porosity of a membrane $\mathrm{Pr}$ and existing probabilities of three kinds of pores such as through-, semi-open, and isolated pores, i.e., $P_{\mathrm{t}}, P_{\mathrm{s}}$, and $P_{\mathrm{i}}$, respectively. ${ }^{9}$

For these ten years, the acquired immune deficiency syndrome (AIDS) virus (human immunodeficiency virus, HIV), hepatitis B and C viruses (HBV and HCV), all of which infect through blood, have been attracting enormous attention, and establishment of a method for effective removal of these disease viruses from human blood is urgently expected for a purification technique of a fractionated blood plasma derivatives and for a clinical therapy. Any possible membrane designed for the removal of virus from aqueous serum protein mixtures should have (1) an extremely high rejection rate (usually, higher than $99.99 \%$ ) of virus and (2) a very 
large permeability of serum proteins.

During $1920 \mathrm{~s}-1930 \mathrm{~s}$, Elford ${ }^{10}$ made a pioneering study of the ultrafiltration of viruses, and disclosed, for example, that the mixture of viruses having different size was separated by an ultrafiltration membrane with proper pore size, and that membranes of progressively lower pore size could be quantitatively resolved a mixture of the virus and hemoglobin. ${ }^{11}$ These facts indicated that "ready filterability" was never indispensable characteristics of viruses. Since then, many works ${ }^{12}$ were accomplished mainly in fields of virology and water processing with a view to concentrate and purify virus and also to estimate size of viruses.

In the late $1980 \mathrm{~s}$, Hamamoto et al. ${ }^{14}$ found that porous regenerated cellulose membrane prepared by the phase separation method with mean pore diameter ranging from 20 to $100 \mathrm{~nm}$ and having sharp pore radius distribution enables to remove exclusively disease viruses contaminated in useful blood plasma.

In the separation of these contaminated disease viruses from blood plasma proteins, it is thought to be more effective and also more concrete to separate the proteins from the viruses by membrane separation based on size exclusion mechanism than to adsorb only the viruses according to their surface properties, because the difference in size between viruses and proteins is generally large enough to distinguish them, but the difference in surface properties between them is rather small.

In case of using either cylindrical pore or network-like pore, if sizes of pores on membrane surface are smaller than those of virus particles, viruses plug pores one by one at its entrance, and filtration rate decreases rapidly as time goes on; this type of membrane is not suitable to treat large amount of blood plasma protein mixtures in order to separate virus from it effectively and concretely.

Tsurumi et al. ${ }^{15,16}$ prepared regenerated cellulose hollow fiber membranes by the phase separation method and estimated that its average pore diameter by waterflow rate method was about $50 \mathrm{~nm}$, disclosing that the membrane was constituted from cellulose particles with mean diameter of about $50 \mathrm{~nm}$ as its constructing units, and that the membrane had two types of pores, one of which is "capillaries" with a diameter of several tens nm, and the other is "void" with the diameter of several hundreds nm having bulky block-like space. By filtration of suspension of colloidal gold particles through the membrane, they considered that the capture mechanism of the particles by the membrane is classified, as plugging in "capillaries" and trapping in "voids," and that the colloidal gold particles proceeded in the membrane from the inner surface to the outer surface gradually when the voids near the inner surface are occupied by gold particles.

Unfortunately, they did not neither demonstrate complete rejection of particles from the filtrate nor clarify accurately the separation mechanism of viruses through porous polymeric membranes, because colloidal gold particle filtration has following limitations: a) spectrophotometric analysis of colloidal gold particles in suspension using spectrophotometry at $530 \mathrm{~nm}$ of wave length was not so sensitive to evaluate changes of particle concentration in filtrate, especially during an early stage of filtration; b) colloidal gold particles have its size distribution, and c) interaction between colloidal gold particles and the membrane was significantly different from that between virus particles and the membrane. For these reasons, complete elimination of viruses from the filtrate should be examined not by separating colloidal gold particles, but by actual virus particles, and this must be the only and the best way for clarifying the mechanism of virus separation through porous polymeric membranes.

In this article, by filtration of suspensions of $E$. coli phage T4 through porous regenerated cellulose hollow fiber membranes, we attempted (1) to investigate the relationship between the permeation properties (i.e., filtration rate and filtration coefficient) and filtration conditions, (2) to demonstrate the possibility of complete rejection of viruses from filtrate, (3) to clarify the captured state of viruses and the concentration distribution of captured virus in the membrane, and (4) to clarify the mechanism of capturing viruses through use of porous regenerated cellulose membranes prepared by the phase separation method, taking into consideration a three-dimensional structure of the membrane, as revealed by an electron microscopic observation and by computer simulation concerning the membrane formation.

\section{EXPERIMENTAL}

\section{Membrane Preparation}

Regenerated cellulose hollow fibers were prepared by coagulating cuprammonium cellulose solutions under the strictly controlled spinning conditions. ${ }^{17,18}$

\section{Membrane Characteristics}

Porosity of Membrane. The porosity of membrane was directly evaluated from the apparent density of membrane $d_{\mathrm{A}}$ and the density of the materials constructing the membrane $d_{\mathrm{PL}}$ through use of eq 1. The porosity, determined by this method, was denoted as $\operatorname{Pr}\left(\mathrm{d}_{3}\right){ }^{7}$

$$
P\left(\mathrm{~d}_{3}\right)=1-\frac{d_{\mathrm{A}}}{d_{\mathrm{PL}}}
$$

where $d_{\mathrm{A}}=w_{\mathrm{m}} / v_{\mathrm{m}}\left(w_{\mathrm{m}}, v_{\mathrm{m}}\right.$ are weight and volume of absolute dry membrane, respectively), and $d_{\mathrm{PL}}=1.564$ $\mathrm{g} \mathrm{ml}^{-1}$ (density of crystalline cellulose ${ }^{19}$ ).

By using an image processor (model IP-1000, Asahi Chemical Industry Co., Ltd., Tokyo, Japan) the porosity of the membrane was evaluated by area fraction of all pores from an transmission electron micrograph of a cross-section of a membrane and was referred to as $\operatorname{Pr}\left(\mathrm{d}_{4}\right) . \operatorname{Pr}\left(\mathrm{d}_{4}\right)$ was converted to apparent phase ratio $R_{\mathrm{A}}$ by the relation, ${ }^{7}$

$$
R_{\mathrm{A}}=\frac{\operatorname{Pr}\left(\mathrm{d}_{4}\right)}{1-\operatorname{Pr}\left(\mathrm{d}_{4}\right)} .
$$

$R_{\mathrm{A}}$ is corresponding to volume ratio of pore to cellulose in a real membrane.

Mean Pore Radius by Water-Flow-Rate Method. The mean pore radius determined by the water-flow-rate method $r_{\mathrm{f}}[\mathrm{m}]$ was calculated by eq $3,{ }^{20}$ 


$$
r_{\mathrm{f}}=\sqrt{\frac{8 \eta_{\mathrm{H}_{2} \mathrm{O}} J L_{\mathrm{d}}}{\operatorname{Pr}\left(\mathrm{d}_{3}\right) \Delta P}},
$$

where $J\left[\mathrm{~m}^{3} \mathrm{~m}^{-2} \mathrm{~s}^{-1}\right]$ is the filtration volume rate per unit area of a membrane; $L_{\mathrm{d}}[\mathrm{m}]$, thickness of dry membrane; $\eta_{\mathrm{H}_{2} \mathrm{O}}\left[\mathrm{Ns} \mathrm{m}^{-2}\right]$, the viscosity of water, and $\Delta P\left[\mathrm{Nm}^{-2}\right]$, loaded pressure. Note that eq 3 was derived under the assumption that all pores were straightthrough cylindrical pores.

\section{Suspension of Virus}

Esherichia coli (IFO13168) was cultivated at $37^{\circ} \mathrm{C}$ in $1 \mathrm{wt} \%$ peptone medium made of Bacto-peptone (Difco Laboratories, MI, U.S.A.), $0.2 \mathrm{wt} \%$ yeast extract (Difco Laboratories, U.S.A.), $0.2 \mathrm{wt} \% \mathrm{NaCl}$ (Kishida Chemical Co., Ltd., Osaka, Japan), whose pH was adjusted at 7.0. After 12 hour incubation, $1.0 \mathrm{ml}$ of the medium was mixed with $10 \mathrm{ml}$ of soft agar medium, which consisted of the peptone medium and $0.8 \mathrm{wt} \%$ agar powder (Wako Pure Chemical Ind. Ltd., Osaka, Japan) and kept at $50^{\circ} \mathrm{C}$. The mixture was poured into a petri dish immediately. After the soft agar was solidified, $0.1 \mathrm{ml}$ of suspension of Bacteriophage T4 (IFO20004; referred to as T4 phage), which contained $c a \cdot 10^{5} \mathrm{PFU}$ (plaque forming unit) per $\mathrm{ml}$, was spread out on a surface of the soft agar plate. Incubated at $37^{\circ} \mathrm{C}$ for another 12 hour, four soft agar plates were broken in pieces to scrape off into a $50 \mathrm{ml}$ centrifugation tube. A $5 \mathrm{ml}$ of flesh peptone medium was added to the soft agar pieces in the tube, and the mixture was centrifuged at $9000 \mathrm{rpm}(9800 \mathrm{~g})$ for $10 \mathrm{~min}$. The supernatant liquid was filtered through Millipore filter (Millex-HA, indicated pore diameter $0.45 \mu \mathrm{m}$, Millipore, MA, U.S.A.). The filtrate was used as an original virus suspension.

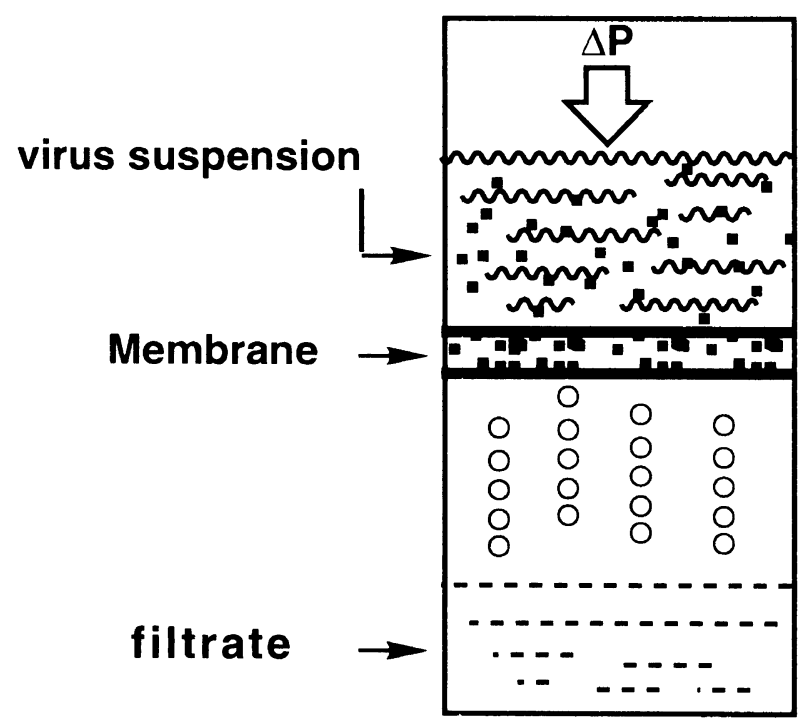

1st step
When effects of concentration of virus in suspensions $c_{0}$ on filtration rate and virus concentration in filtrate were to be examined, an original virus suspension $\left(c_{0}=2.8 \times 10^{10} \mathrm{PFU} \mathrm{ml}^{-1}\right)$ was diluted with fresh peptone medium to prepare virus suspensions having different $c_{0}\left(1.3 \times 10^{9} \mathrm{PFU} \mathrm{m}^{-1} ; 1.4 \times 10^{8} \mathrm{PFU} \mathrm{ml}^{-1}\right)$; concentration of components in these diluted suspensions other than virus particle itself (e.g., proteins, aggregates of agar, cell fragments from $E$. coli) was also reduced in proportion to dilution ratio.

\section{Virus Filtration}

Virus suspension of T4 phage was introduced in the inner space of a single hollow fiber from an one-open end of the fiber, where the other end was closed tightly with an adhesive agent. Filtration area of inner surface of the hollow fiber was $c a .0 .7 \mathrm{~cm}^{2}$, and the suspension was filtrated at $25^{\circ} \mathrm{C}$ under constant pressure difference $\Delta P=200 \mathrm{mmHg}$. Hereafter, this type of filtration was referred to as perpendicular filtration.

Figure 1 shows two-step procedure of virus filtration and rinsing: In order to examine movement of viruses in a membrane during filtration, certain amount of the virus suspension was filtered through a membrane, and immediately after the first step of the virus filtration, the membrane was rinsed by saline water under the same $\Delta P$ and temperature and virus concentration in rinsed saline water was examined.

Concentration of T4 phage in filtrand (i.e., an original solution to be filtered) $c_{0}$ [PFU ml ${ }^{-1}$ ], that in filtrate $c_{\mathrm{f}}$ $\left[\mathrm{PFU} \mathrm{ml} \mathrm{m}^{-1}\right]$, and that in rinsed saline water $c_{\mathrm{f}, \mathrm{r}}$ [PFU ml $\left.{ }^{-1}\right]$ were assayed by the plaque forming method using Esherichia coli (IFO13168) as a host. When the critical filtration volume $V^{\mathrm{c}}$ was to be determined, $c_{\mathrm{f}}$ in every $0.2 \mathrm{ml}$ of filtrate was evaluated from the first

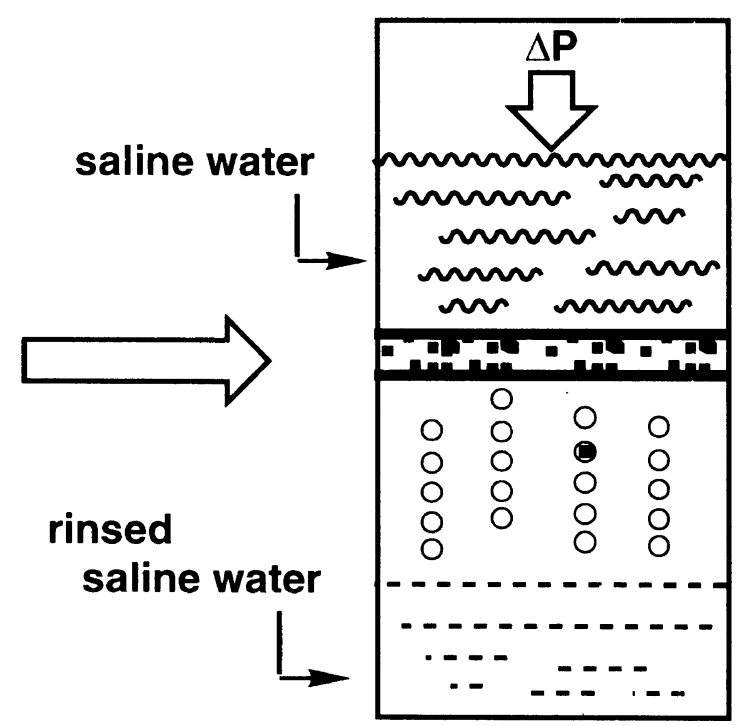

2nd step

Figure 1. Schematic representation of two-step procedure during virus filtration and the following rinsing of the membrane: Dots in virus suspension and also in membrane mean virus particles; white circles represent drops of filtrand or rinsed saline water; a drop with a dot in the second step contains a virus particle. 
fraction during the filtration.

\section{Rejection Coefficient $\Phi_{\mathrm{e}}$}

Virus logarithmic rejection coefficient $\Phi_{\mathrm{e}}$ is defined by eq 4,

$$
\Phi_{\mathrm{e}}=\log \frac{c_{0}}{c_{\mathrm{f}}},
$$

where $c_{0}$ and $c_{\mathrm{f}}$ are concentration of filtrand and filtrate, respectively.

\section{Electron Microscopy}

Immediately after filtration, a porous regenerated cellulose hollow fiber was fixed with a $2 \mathrm{wt} \%$ glutaraldehyde/paraformaldehyde mixture in $0.1 \mathrm{M}$ cacodylate buffer ( $\mathrm{pH} \mathrm{7.4)} \mathrm{for} 30 \mathrm{~min}$. After cutting, small pieces of the fibers were postfixed with $2 \mathrm{wt} \%$ osmic acid for 2 hour, dehydrated with a graded acetone, and embedded in an Epok 812 (Ouken Shoji, Tokyo, Japan). Ultrathin sections were made with an LKB Ultrotome 8800 (manufactured by LKB Co., Sweden), using a glass knife. Stained with $4 \mathrm{wt} \%$ uranyl acetate at first and then with $4 \mathrm{wt} \%$ lead citrate, these ultrathin sections were examined with a transmission electron microscope (TEM; type JEM-1200EX, manufactured by JEOL Ltd., Tokyo, Japan). Number of viruses was counted using micrographs to determine concentration distribution of virus $C_{\mathrm{m}}$ in each unit layer [number $\mathrm{cm}^{-2}$ ].

\section{RESULTS AND DISCUSSION}

\section{Morphology of Pores and Conditions of Viruses Captured in Pores}

Figure $2 \mathrm{a}$ shows an transmission electron micrograph of a cross-section of porous regenerated cellulose hollow fiber membrane $\left(2 r_{\mathrm{f}}=41 \mathrm{~nm}\right)$ which had captured T4 phage in the process of the perpendicular filtration of suspension of $\mathrm{T} 4$ phage at $\Delta P=200 \mathrm{mmHg}$. In the figure, blackish particles are bacteriophages captured in pores and whitish parts are cellulose constituting the membrane structure. A sketch of T4 phage was shown in Fig- ure 2c. T4 phage is composed of a polyhedral structure (termed head) connected to a helical structure (termed a tail). ${ }^{21}$ Diameter of its head was estimated to be $c a .100$ $\mathrm{nm} .{ }^{22}$ It was found that many cavities scattered in the membrane and lots of narrow veins connecting those cavities, concluding that pores in the membrane consisted of large cavities and veins (cavity-vein structure).

Average width of these narrow veins was approximately $100 \mathrm{~nm}$, which was almost the same as diameter of head of T4 phage. Average diameter of the secondary particles $2 \bar{S}_{2}$ was estimated to be $c a$. $100 \mathrm{~nm}$ by analyzing a scanning electron micrograph of the membrane surface (not shown here). These facts indicated that narrow veins corresponded to pores consisting of vacant particles which connected linearly. ${ }^{7}$ Size of a cavity was much larger than that of a single phage itself.

Figure $2 b$ shows a schematic representation of cavityvein structure and captured viruses in the structure. It was found that a single virus was blocking a narrow vein (this type of capturing is referred to as "blocking") and a huge number of viruses was accumulated and captured in a cavity (referred to as "accumulation").

Figure $3 \mathrm{a}$ shows a transmission electron micrograph of a cross-section of another membrane. By emphasizing contrast between whitish parts (cellulose) and blackish parts (pores) in the figure, we obtained a drawing of a cross-section of the cellulose membrane (Figure $3 b$ ). In this figure, pores are drawn in white in reverse to the expression of Figure 3a. Porosity $\operatorname{Pr}\left(\mathrm{d}_{4}\right)$ evaluated from Figure $3 \mathrm{~b}$ was 0.36 , i.e., an apparent phase volume ratio $R_{\mathrm{A}}$ was $c a$. 0.56 .

Figure $3 \mathrm{c}$ shows a random distribution pattern of polymer particles and vacant particles constructed by the computer simulation technique ${ }^{8}$ under the condition of $R_{\mathrm{A}}=0.56$. In this figure, polymer particles, i.e., cellulose particles, are represented in black and vacant particles are omitted, and not shown here.

Figure $3 \mathrm{~d}$ was drawn by tracing Figure 3c; Pore edges were smoothed to show that pores were consisting of cavities and veins which connected neighboring cavities. Comparing a cross-section of pores by the computer simulation (Figure 3d) with that of an actual cellulose a)

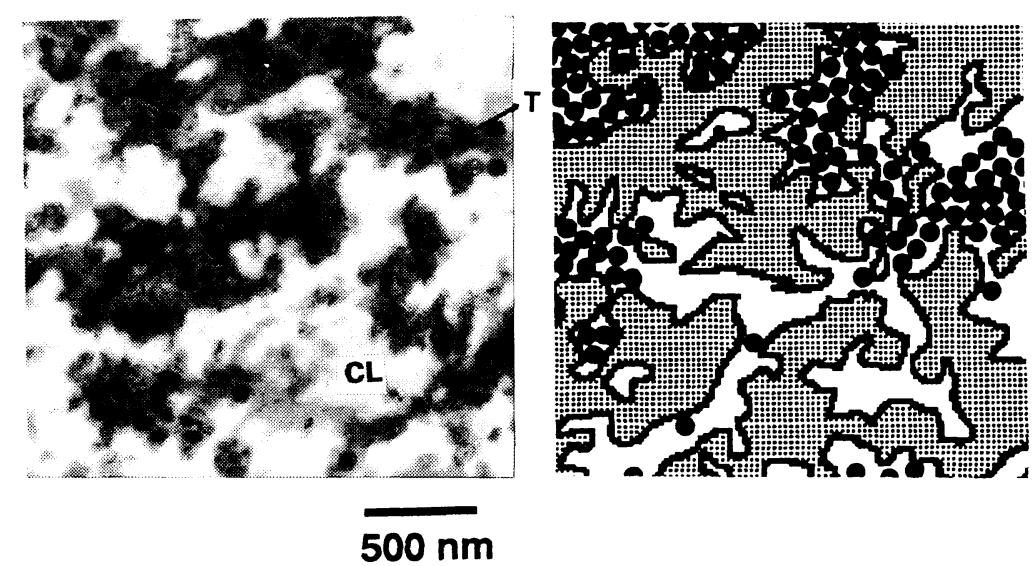

c)

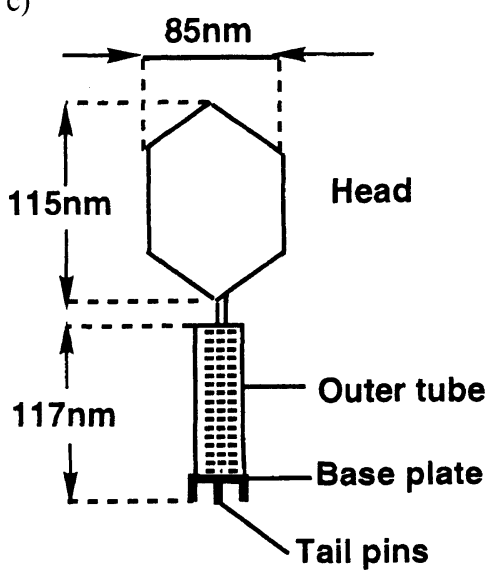

Figure 2. Cross-section of a porous regenerated cellulose membrane and captured viruses in the membrane: a) Transmission electron micrograph of a cross-section of porous regenerated cellulose hollow fiber membrane; $2 r_{\mathrm{f}}=41 \mathrm{~nm}$; T4 phage suspension was filtered through the membrane by perpendicular filtration at $\Delta P=200 \mathrm{mmHg}$; blackish particle (T), T4 phage; whitish part (CL), cellulose; grayish part, pore; inner surface of the membrane was located beyond an upper part of the figure, not shown here; scale bar stands for $500 \mathrm{~nm}$. b) Schematic representation of cavity-vein structure; shadowed area, cellulose; black particle, virus particle; c) Sketch of T4 phage. 
a)

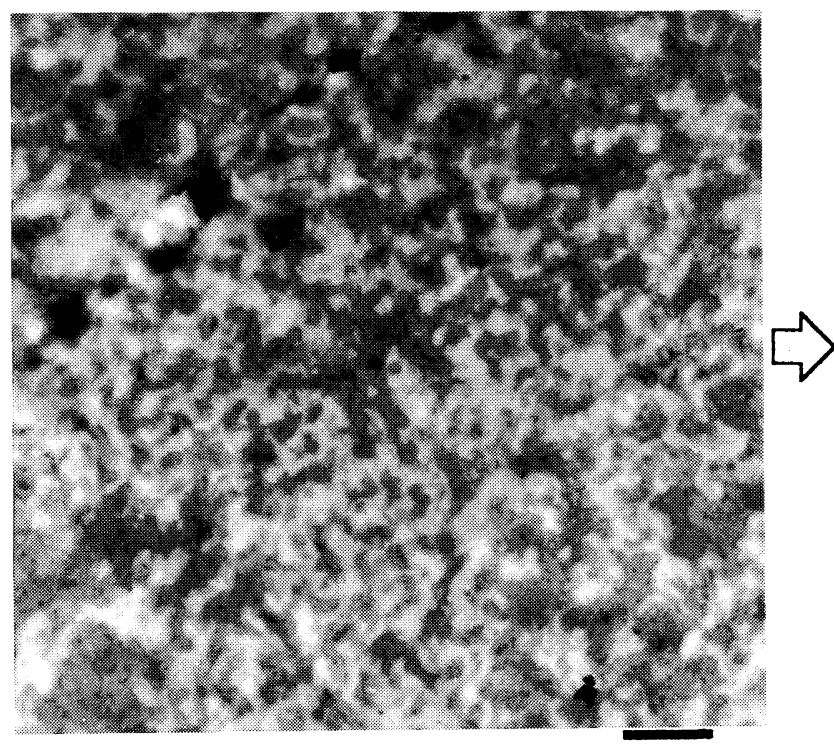

$500 \mathrm{~nm}$

c)

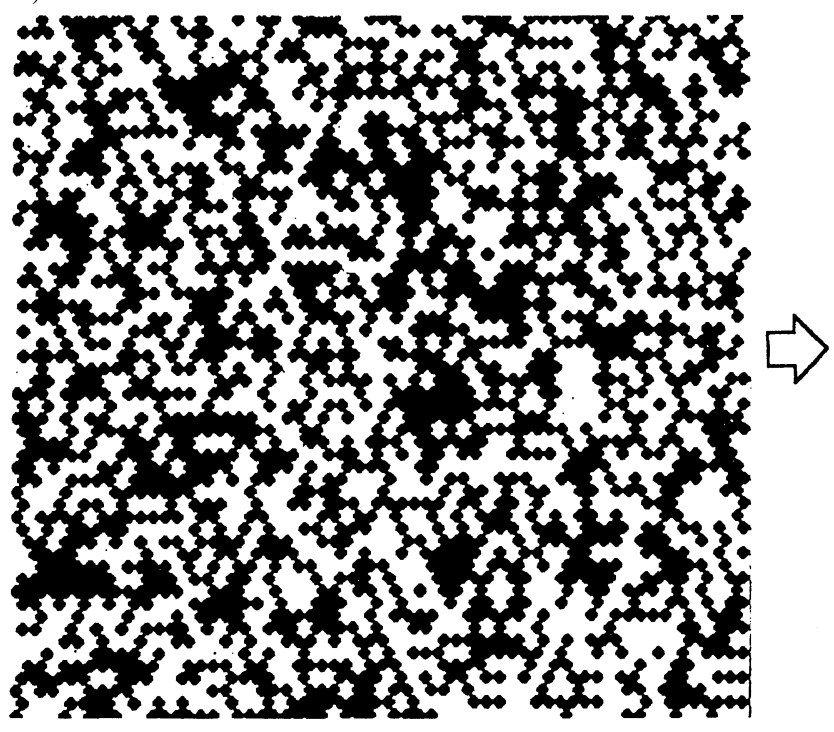

b)

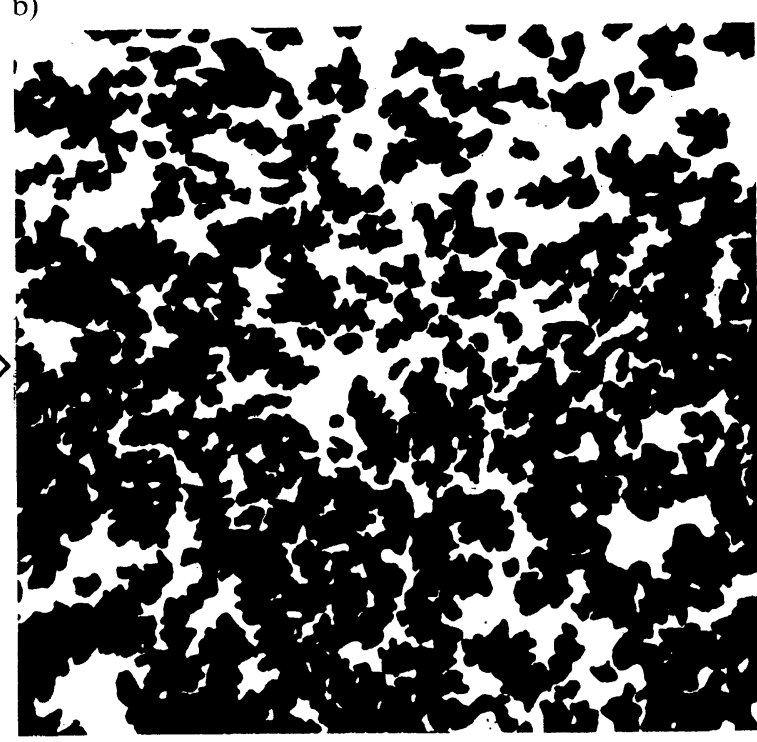

d)

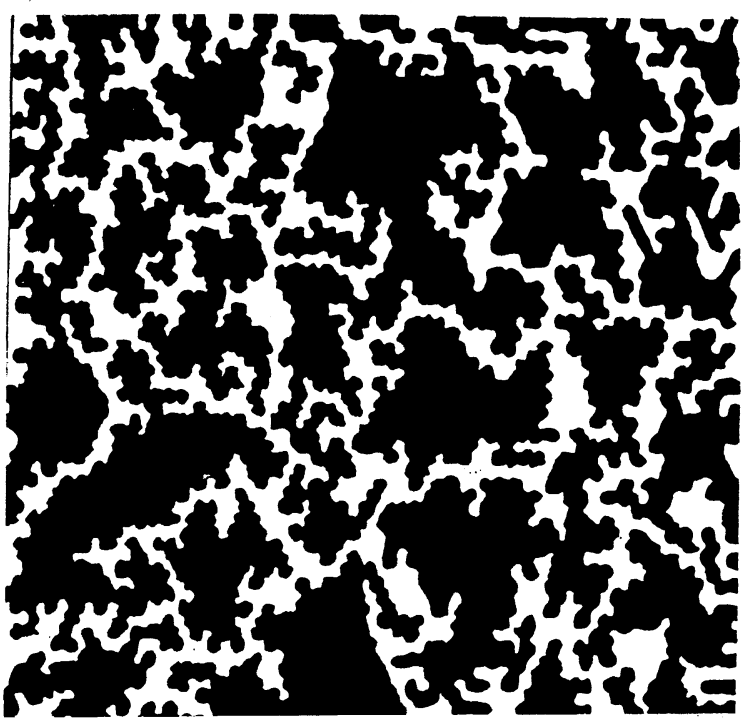

Figure 3. Cross-section of a porous cellulose membrane: a) Transmission electron micrograph of a cross-section of porous regenerated cellulose hollow fiber membrane; area in whitish, cellulose; area in blackish, pore; b) Tracing of Figure 3a; boundary between cellulose and pores was emphasized; white area, pore; black area, cellulose; $\operatorname{Pr}\left(\mathrm{d}_{4}\right)=0.36 ; R_{\mathrm{A}}=0.56$. c) Random distribution pattern of polymer particles and vacant particles by computer simulation; $R_{\mathrm{A}}=0.56$; black particle, polymer particle; vacant particles were omitted, not shown. d) Tracing of Figure 3c; pore edges were smoothed; area drawn in black consists of polymer particles; pores are in white.

membrane observed by TEM (Figure 3b), we could find that the model expressed fairly well characteristics of pores of the actual membrane. Figure 4 shows a schematic representation of the cavity-vein structure of porous polymeric membrane where large cavities connect with each other by narrow veins; a width of vein is almost the same as radius of polymer particle.

According to the computer simulation study on threedimensional structure of the porous polymeric membrane, number of through-pores became unity when the porosity of membrane $\mathrm{Pr}$ was larger than $0.25 .^{9}$ This fact indicates that all vacant particles constituting the through-pore contact with each other to form a single network-like pore. In other word, porous regenerated cellulose membrane has a multi-layer structure forming a single network-like pore where all cavities are connected with each other by narrow veins.

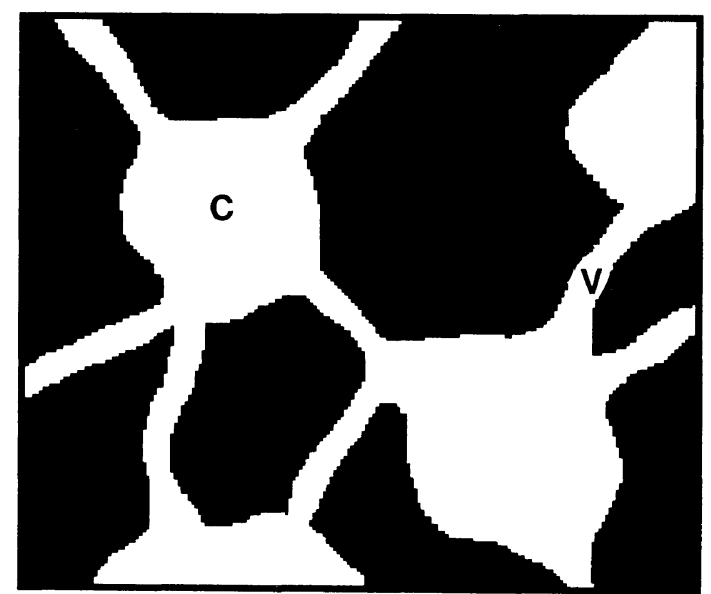

Figure 4. Schematic representation of cavity-vein structure of porous polymeric membrane: $\mathrm{C}$, cavity; $\mathrm{V}$, vein; black part, polymer. 


\section{Movement of Viruses in Membranes}

Table I shows changes in virus concentration in filtrate obtained in the first step shown in Figure 1 (i.e., $c_{\mathrm{f}}$ ) and those in rinsed saline water obtained in the second step in the same figure (i.e., $c_{\mathrm{f}, \mathrm{r}}$ ). The porous regenerated cellulose hollow fiber membrane $\left(2 r_{\mathrm{f}}=c a .25 \mathrm{~nm}\right)$, which had already filtered a certain amount of virus suspension (T4 phage; $c_{0}=5.66 \times 10^{9} \mathrm{PFU} \mathrm{ml}^{-1}$ ) at $\Delta P=200 \mathrm{mmHg}$, was rinsed by saline water at $\Delta P=200 \mathrm{mmHg}$. As shown in the 4th column of the table, no virus was contaminated in the filtrate (i.e., $\left.c_{\mathrm{f}}=0\right)$ as much as total volume of applied virus suspension in unit area of membrane $V_{\mathrm{T}}$ was in a range of 3.45 to $4.00 \mathrm{ml} \mathrm{cm}^{-2}$. When total volume of rinsed saline water per unit area of membrane during the rinsing $V_{\mathrm{T}, \mathrm{r}}$ was $1.00 \mathrm{ml} \mathrm{cm}^{-2}$ or $6.00 \mathrm{ml} \mathrm{cm}^{-2}$, no viruses appeared in the rinsed saline water, but in case of $V_{\mathrm{T}, \mathrm{r}}=18.4 \mathrm{ml} \mathrm{cm}^{-2}, c_{\mathrm{f}, \mathrm{r}}$ was 7.0 PFU ml ${ }^{-1}$, i.e., virus particles corresponding to 128.8 PFU passed through an unit area of the membrane.

As porous membrane has unavoidably pore size distribution, ${ }^{7,8}$ even if average diameter of porous membrane $2 r_{\mathrm{f}}$ was less than one third of diameter of virus particle, a very few of viruses, e.g., one virus among $10^{9}$ particles, flew through the pore structure during the rinsing.

As far as efficiency and performance of virus separation through porous membrane are simply dominated by size exclusion mechanism, viruses slip out through the network-like structure sometime during the filtration, but we should note that the appearance of viruses in the filtrate was delayed for a fairly long time and that the filtrate obtained during this period was completely free from virus.

Figure 5 shows number distribution of viruses in unit area of unit layer inside membrane $C_{\mathrm{m}}$ [number $\mathrm{cm}^{-2}$ ] in cases of a) before rinsing and b) after rinsing. Conditions of the filtration and the rinsing were as follows: $2 r_{\mathrm{f}}=59.7 \mathrm{~nm} ; \Delta P=200 \mathrm{mmHg} ;$ and concentration of viruses $c_{0}=1.4 \times 10^{10} \mathrm{PFU} \mathrm{ml}^{-1} ; V_{\mathrm{T}}=5.0 \mathrm{ml} \mathrm{cm}^{-2}$. In case of the rinsing, total volume of the rinsed saline water during the rinsing $V_{\mathrm{T}, \mathrm{r}}$ was $30.0 \mathrm{ml} \mathrm{cm}^{-2}$. In the figure, depth from an inner surface of a hollow fiber membrane is normalized as $L / L_{\mathrm{d}}$. Before the rinsing (Figure 5a), an end of the distribution reached to $L / L_{\mathrm{d}}=0.7$, whereas

Table I. Changes in virus concentration in filtrate during a rinsing of a membrane with saline water after virus filtration ${ }^{\mathrm{a}}$

\begin{tabular}{|c|c|c|c|c|c|}
\hline $2 r_{\mathrm{f}}^{\mathrm{b}}$ & $V_{\mathrm{T}}^{\mathrm{c}}$ & $C_{\mathrm{T}}^{\mathrm{d}}$ & $c_{\mathrm{f}}^{\mathrm{e}}$ & $V_{\mathrm{T}, \mathrm{r}}^{\mathrm{f}}$ & $c_{\mathrm{f}, \mathrm{r}}^{\mathrm{g}}$ \\
\hline $\mathrm{nm}$ & $\mathrm{ml} \mathrm{cm}^{-2}$ & $\mathrm{PFU} \mathrm{cm}^{-2}$ & $\mathrm{PFU} \mathrm{ml}^{-1}$ & $\mathrm{ml} \mathrm{cm}^{-2}$ & $\mathrm{PFU} \mathrm{ml}^{-1}$ \\
\hline 23.1 & 3.45 & $1.95 \times 10^{10}$ & 0 & - & - \\
\hline 25.5 & 4.00 & $2.26 \times 10^{10}$ & 0 & 1.00 & 0 \\
\hline 25.2 & 3.49 & $1.98 \times 10^{10}$ & 0 & 6.00 & 0 \\
\hline 22.4 & 3.54 & $2.00 \times 10^{10}$ & 0 & 18.4 & 7 \\
\hline
\end{tabular}

a Thickness of membrane $L_{\mathrm{d}}, 23.1 \mu \mathrm{m}$; inner diameter of hollow fiber $D_{0 \mathrm{i}}, 315 \mu \mathrm{m}$; concentration of viruses $c_{0}, 5.66 \times 10^{9}\left(\mathrm{PFU} \mathrm{ml}^{-1}\right)$. ${ }^{\mathrm{b}} r_{\mathrm{f}}$, mean pore radius determined by the water-flow rate method. ${ }^{\mathrm{c}} V_{\mathrm{T}}$, total volume of applied virus suspension in unit area of membrane. ${ }^{\mathrm{d}} C_{\mathrm{T}}$, total number of viruses loaded to membrane. ${ }^{\mathrm{e}} c_{\mathrm{f}}$, concentration of $\mathrm{T} 4$ phage in filtrate. ${ }^{\mathrm{f}} V_{\mathrm{T}, \mathrm{r}}$, total volume of rinsed saline water per unit area of membrane during rinsing. ${ }^{\mathrm{g}} c_{\mathrm{f}, \mathrm{r}}$, concentration of virus in rinsed saline water. after the rinsing (Figure $5 \mathrm{~b}$ ) width of the distribution became broader to $L / L_{\mathrm{d}}=0.9$. This result also pointed out the fact that a part of virus particles moved to go downstream in the membrane during the rinsing.

Figure 6 shows changes in distribution of $C_{\mathrm{m}}$ during virus filtration. Condition of filtration was as follows: $2 r_{\mathrm{f}}=37.9 \mathrm{~nm} ; \Delta P=200 \mathrm{mmHg}$; and concentration of viruses $c_{0}=5.5 \times 10^{9} \mathrm{PFU} \mathrm{ml}{ }^{-1}$. With an increase in $V_{\mathrm{T}}$, a peak of $C_{\mathrm{m}}$ shifted downstream and also width of $C_{\mathrm{m}}$ distribution became broader. The filtration of virus

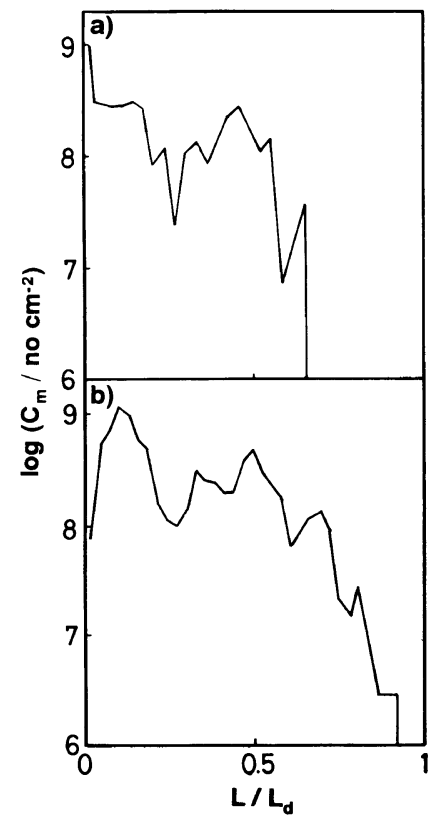

Figure 5. Effect of rinsing after virus filtration on number distribution of viruses in unit area of a single layer in membrane $C_{\mathrm{m}}: 2 r_{\mathrm{f}}$, $59.7 \mathrm{~nm} ; \Delta P, 200 \mathrm{mmHg} ; c_{0}, 1.4 \times 10^{10} \mathrm{PFU} \mathrm{ml}^{-1} ; V_{\mathrm{T}}, 5.0 \mathrm{ml} \mathrm{cm}^{-2}$; $L / L_{\mathrm{d}}$, normalized depth from an inner surface of a hollow fiber membrane; a) before rinsing; b) after rinsing; total volume of filtrate during the rinsing per unit area of membrane $V_{\mathrm{T}, \mathrm{r}}=30.0 \mathrm{ml} \mathrm{cm}^{-1}$.

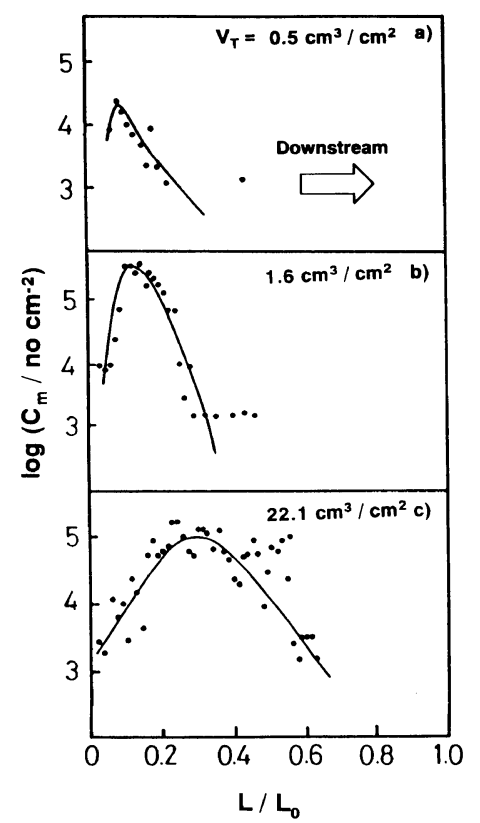

Figure 6. Changes of number distribution of viruses in unit area of a single layer in membrane $\mathrm{C}_{\mathrm{m}}$ during virus filtration: $2 r_{\mathrm{f}}, 37.9 \mathrm{~nm} ; \Delta P$, $200 \mathrm{mmHg} ; c_{0}, 5.5 \times 10^{9} \mathrm{PFU} \mathrm{ml}^{-1} ; L / L_{\mathrm{d}}$, normalized depth from an inner surface of a hollow fiber membrane; a) Total filtration volume $V_{\mathrm{T}}=0.5 \mathrm{ml} \mathrm{cm}^{-2}$; b) $V_{\mathrm{T}}=1.6 \mathrm{ml} \mathrm{cm}^{-2} V_{\mathrm{T}}$; c) $V_{\mathrm{T}}=22.1 \mathrm{ml} \mathrm{cm}^{-2}$. 


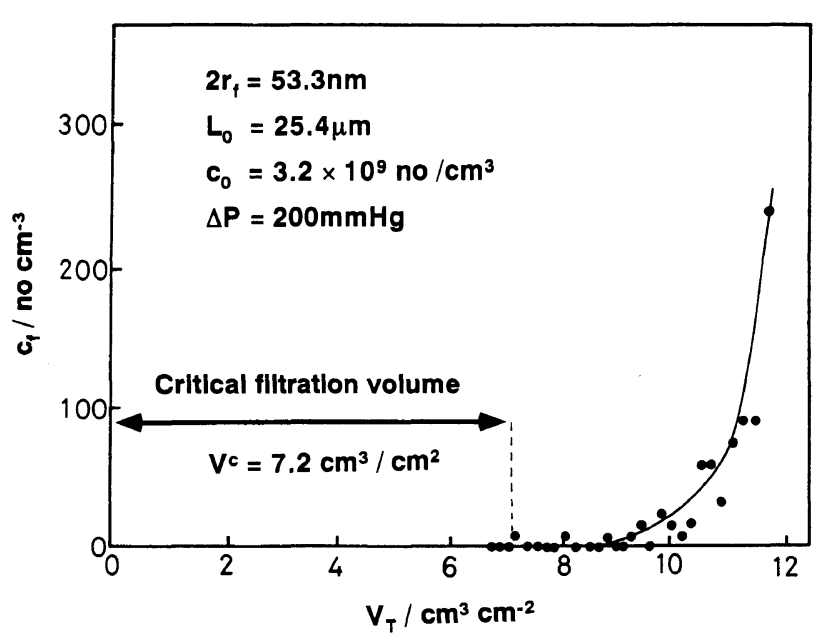

Figure 7. Change of virus concentration $c_{\mathrm{f}}$ during filtration: $2 r_{\mathrm{f}}$, $53.3 \mathrm{~nm} ; L_{\mathrm{d}}, 25.4 \mu \mathrm{m} ; \Delta P, 200 \mathrm{mmHg} ; c_{0}, 3.2 \times 10^{9} \mathrm{PFU} \mathrm{ml}^{-1}$; volume of every fraction was $c a .0 .2 \mathrm{ml} ; V^{\mathrm{c}}, 7.2 \mathrm{ml} \mathrm{cm}^{-2}$.

through the membranes can be regarded as multi-stage filtration, and most of them are captured effectively in cavities and in veins, but extremely a small number of viruses can squeeze through veins and cavities to flow downstream.

\section{Critical Filtration Volume}

Figure 7 shows the plots of virus concentration $c_{\mathrm{f}}$ during the filtration carried out under condition that $2 r_{\mathrm{f}}=53.3 \mathrm{~nm} ; \Delta P=200 \mathrm{mmHg} ; c_{0}=3.2 \times 10^{9} \mathrm{PFU} \mathrm{ml}^{-1}$ against total volume of filtrate $V_{\mathrm{T}}$. Here, $c_{\mathrm{f}}$ means the virus concentration of a single drop of filtrate (ca. $0.2 \mathrm{ml})$ at the instance total volume (accumulated volume) of filtrate attained $V_{\mathrm{T}}$. Every $0.2 \mathrm{ml}$ of filtrate was fractionated to determine virus concentration by plaque assay. Until $V_{\mathrm{T}}$ amounted to $7.2 \mathrm{ml} \mathrm{cm}^{-2}$, absolutely no virus particle appeared in the filtrate, but after the first virus arrived at the opposite side of the membrane, i.e., the outer surface of the hollow fiber membrane, virus particles detected not in every fraction, but in every several fractions. Over the range of $V_{\mathrm{T}}$ larger than $10 \mathrm{ml} \mathrm{cm}^{-2}, \quad c_{\mathrm{f}}$ increased rapidly. Virus logarithmic rejection coefficient $\Phi_{\mathrm{e}}$ was 8.6 at $V_{\mathrm{T}}=10 \mathrm{ml} \mathrm{cm}^{-2}, 7.5$ at $11.8 \mathrm{ml} \mathrm{cm}^{-2}$.

It should be a remarkable fact that complete rejection of viruses from the filtrate was achieved in a range of $V_{\mathrm{T}}<7.2 \mathrm{ml} \mathrm{cm}^{-2}$. We define a "critical filtration volume $V^{\mathrm{c}}\left[\mathrm{ml} \mathrm{cm}{ }^{-2}\right]$ " as $V_{\mathrm{T}}$ at the moment when the first virus appears in the filtrate. In this experiment, $V^{\mathrm{c}}$ is 7.2 $\mathrm{ml} / \mathrm{cm}^{-2}$. Until the total filtration volume reaches $V^{\mathrm{c}}$, we can get the filtrate free from virus by using porous cellulose membrane. Without exceeding its $V^{\mathrm{c}}$, the porous cellulose membrane will be one of possible membranes designed for the removal of virus from aqueous serum protein mixtures.

\section{Dependence of Critical Filtration Volume on Filtration Pressure}

Figure 8 shows an effect of filtration pressure $\Delta P$ on critical filtration volume $V^{\mathrm{c}}$ (Figure $8 \mathrm{a}$ ) and that on filtration coefficient $v_{\mathrm{f}}^{\prime}\left(\equiv v_{\mathrm{f}} / \Delta P\right.$; Figure $8 \mathrm{~b}, v_{\mathrm{f}}$ is filtration rate per unit area of a membrane). In order to maintain a high filtration rate at the pressure range of $50 \mathrm{mmHg}<$

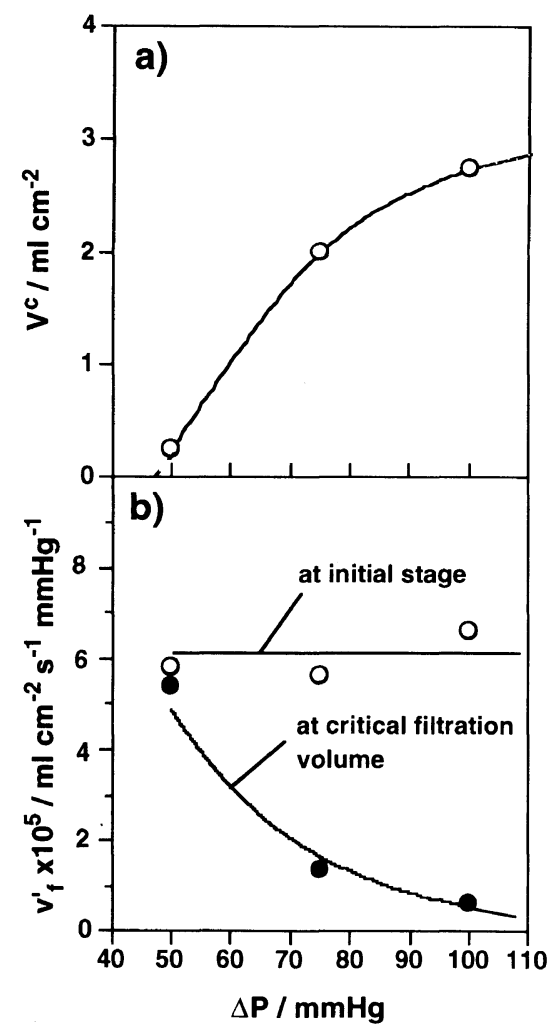

Figure 8. Effect of filtration pressure $\Delta P$ on critical filtration volume $V^{\mathrm{c}}$ and filtration coefficient $v_{\mathrm{f}} / \Delta P: 2 r_{\mathrm{f}}, 98 \mathrm{~nm} ; c_{0}, 1.36 \times 10^{10} \mathrm{PFU} \mathrm{ml}^{-1}$; a) Relationship between $V^{\mathrm{c}}$ and $\Delta P$; b) relationship between $v_{\mathrm{f}} / \Delta P$ and $\Delta P$; open circle, at an initial stage of filtration; closed circle, at critical filtration volume.

$\Delta P<100 \mathrm{mmHg}$, cellulose membranes having rather large pore size $\left(2 r_{\mathrm{f}}=98 \mathrm{~nm}\right)$ were employed. Concentration of filtrand $c_{0}$ was $1.36 \times 10^{10} \mathrm{PFU} / \mathrm{cm}^{-2}$.

In Figure $8 \mathrm{a}$, the higher the loaded pressure $\Delta P$ was, the more viruses were captured in membranes. With a decrease in $\Delta P, V^{\mathrm{c}}$ decreased gradually, and at a range below $45 \mathrm{mmHg}, V^{\mathrm{c}}$ became actually to be zero, that is, immediately after a filtration was started, viruses would appear in the filtrate.

Figure $8 \mathrm{~b}$ shows that filtration coefficient $v_{\mathrm{f}}^{\prime}$ was almost constant at an initial stage of filtration. In other words, the filtration rate $v_{\mathrm{f}}$ was in rough proportion to $\Delta P$, indicating that compression of pore structure in the membrane due to application of $\Delta P$ during filtration was actually negligible and also that pore size didn't change significantly in this pressure range employed. It seems that transformation of virus particle due to pressure was also insignificant at $\Delta P$ below $100 \mathrm{mmHg}$. Note that without any changes neither in size of pores during the filtration nor in size of viruses in the filtrand, number of veins which should be blocked by a single virus was not changed in this pressure range.

From these results, it is appropriate to consider that number of viruses captured by the blocking should be almost constant and quite small at $\Delta P$ below $100 \mathrm{mmHg}$. These things lead us to the conclusion that the capacity of the accumulation of viruses in a membrane is strongly dependent on $\Delta P$, and that the accumulation occurs more frequently at higher $\Delta P$.

Closed circles in Figure $8 \mathrm{~b}$ represent $v_{\mathrm{f}}^{\prime}$ at critical filtration volume $V^{\mathrm{c}}$ for various $\Delta P$. In case of $\Delta P=$ 


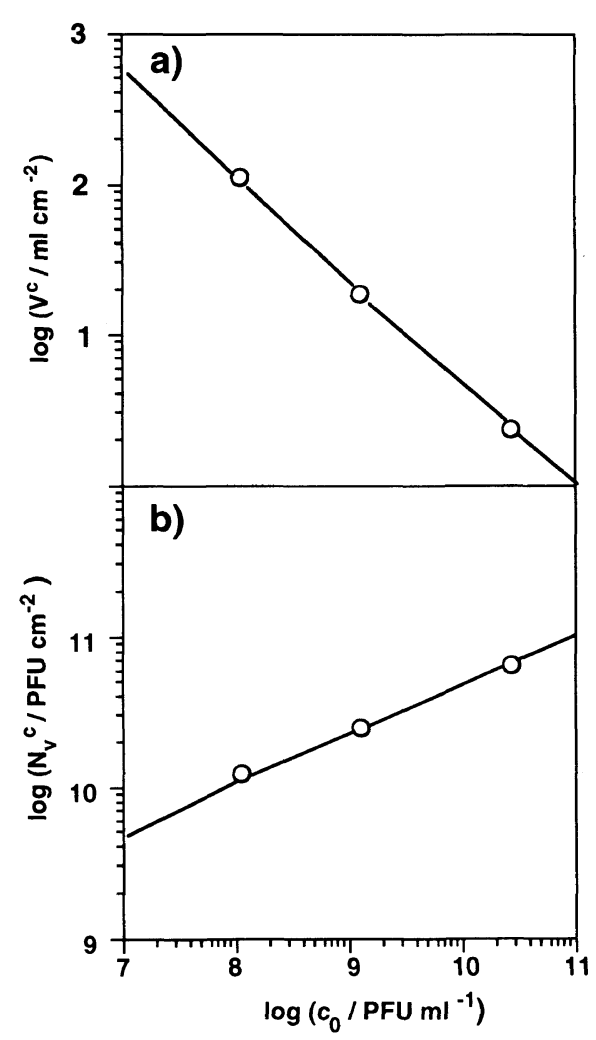

Figure 9. Effects of virus concentration in filtrand $c_{0}$ on capacity of membrane in capturing viruses: $2 r_{\mathrm{f}}, 97.2-101.5 \mathrm{~nm} ; \Delta P, 200 \mathrm{mmHg}$; a) Relation between critical filtration volume $V^{\mathrm{c}}$ and $c_{0}$; b) Relation between number of viruses captured in unit area of membrane at a critical filtration volume $N_{\mathrm{v}}^{\mathrm{c}}$ and $c_{0}$.

$50 \mathrm{mmHg}, v_{\mathrm{f}}^{\prime}$ at $V_{\mathrm{c}}$ was almost the same as that at an initial stage. With an increase in $\Delta P, v_{\mathrm{f}}^{\prime}$ decreases, indicating the membrane captured viruses more effectively by accumulating them in the cavities at higher pressure. The accumulation of viruses in the cavity should be thoroughly affected by loaded pressure, i.e., by flow rate in pores.

\section{Dependence of Critical Filtration Volume on Virus Con- centration of Suspension, Filtration Rate, and Num- ber of Loaded Viruses to Membrane}

Figure 9 shows effects of virus concentration in filtrand $c_{0}$ on the critical filtration volume $V^{\mathrm{c}}$ (Figure 9a) and on the number of viruses captured in unit surface area of membrane at a critical filtration volume $N_{\mathrm{v}}^{\mathrm{c}}$ (Figure $9 b)$. With an increase in $c_{0}, V^{\mathrm{c}}$ decreased, but $N_{\mathrm{v}}^{\mathrm{c}}$ increased on the contrary, suggesting that more viruses were captured by the accumulation at higher $c_{0}$.

Figure 10 shows that an effect of virus concentration $c_{0}$ on the relation between $v_{\mathrm{f}}$ and a total number of viruses loaded to membrane $C_{\mathrm{T}}\left[\mathrm{PFU} \mathrm{cm}{ }^{-2}\right]$. In different virus suspensions, concentrations of foreign particles, e.g., pieces of agar aggregates and cell fragments were reduced in proportion to dilution ratio. Accordingly, when we compare the values $v_{\mathrm{f}}$ at the same $C_{\mathrm{T}}$ obtained in different runs of filtration with each other, an effect of captured foreign particles on $v_{\mathrm{f}}$ is negligible. Furthermore, number of viruses passing through the membrane could be disregarded as compared with $C_{\mathrm{T}}$, so that number of viruses existing in the membrane was regarded almost equal to $C_{\mathrm{T}}$.

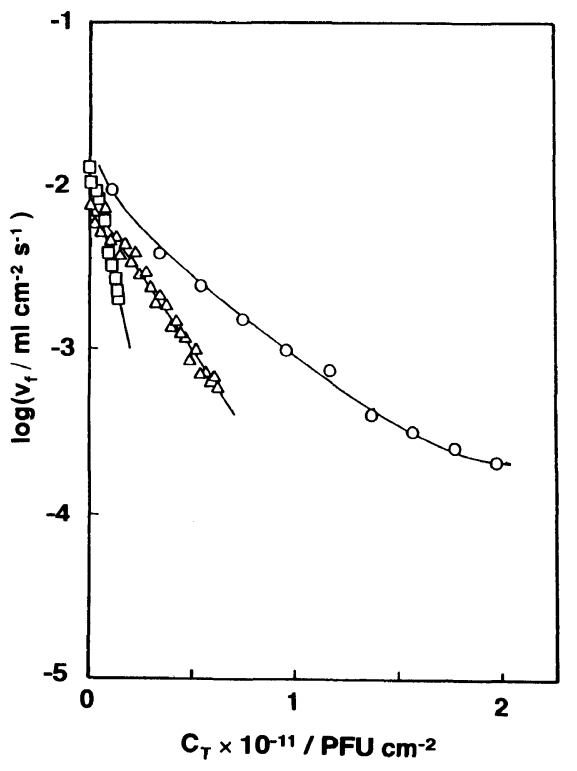

Figure 10. Effect of virus concentration $c_{0}$ on the relation between

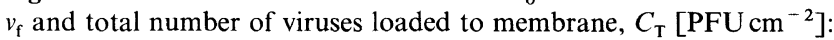
$2 r_{\mathrm{f}}, 97.2-101.5 \mathrm{~nm} ; \Delta P, \quad 200 \mathrm{mmHg} ;$ open circle, $c_{0}=2.8 \times 10^{10}$ PFU ml ${ }^{-1}$; open triangle, $1.3 \times 10^{9} \mathrm{PFU} \mathrm{ml}^{-1}$; open square, $1.4 \times 10^{8}$ PFU ml-1.

When $C_{\mathrm{T}}$ was the same, $v_{\mathrm{f}}$ was higher for higher $c_{0}$, indicating that there existed more blocked veins at lower $c_{0}$. On the other hand, comparison of $C_{\mathrm{T}}$ at the same $v_{\mathrm{f}}$ shows that $C_{\mathrm{T}}$ is larger, i.e., more viruses are captured at higher $c_{0} \cdot v_{\mathrm{f}}$ seems to be proportional to the number of through-paths. These facts indicated that 1) viruses tended to be easily accumulated in cavities at higher $c_{0}$, and that 2) there existed more blocked veins at lower $c_{0}$.

In general, an outer coat of a virus may be a protein capsid which is constructed from protein molecules or a membrane envelope which contains lipid as well as protein. ${ }^{23}$ For example, T4 phage has the former type of the outer surface, ${ }^{24}$ and $\mathrm{HBV}^{24}$ and $\mathrm{HIV}^{25}$ have the latter type.

The porous cellulose membrane used in this study was prepared by regenerating cuprammonium cellulose, and it shows hydrophilic properties of cellulose itself. Irrespective of whether a virus has an envelope or not, an interaction between the surface of regenerated cellulose membrane and the virus particle is thought to be very small, because the membrane seldom adsorb neither protein ${ }^{26}$ nor lipid.

In this study, it was found that the mechanism of virus rejection by the porous regenerated cellulose membrane was not based on the specific adsorption of virus particles on membrane surface, but on the physical rejection of virus particles such as the blocking in veins $(=$ size exclusion) and the accumulation in cavities (=trapping). In the filtration with the porous regenerated cellulose membrane, it is possible to enhance the efficiency of the virus separability in both preciseness and filtration volume. Accordingly, the results obtained in this study would be applied in cases of rejecting $\mathrm{HBV}, \mathrm{HCV}$, and HIV from blood plasma.

Furthermore, by using a porous polymeric membrane having the same structure as that of the porous regenerated cellulose membrane and also showing a mere interaction between virus and polymer itself, the results 
obtained here would be applied, regardless of kinds of viruses, in any cases of virus rejection from aqueous solutions including blood plasma.

\section{CONCLUSIONS}

1) A porous membrane prepared by the phase separation method consists of polymer particles and the membrane has "cavity-vein structure."

2) Viruses were captured by two different manners; accumulation in cavities and blocking of narrow veins.

3) Viruses moved downstream in the membrane, flowing out in the filtrate, however, without exceeding its "critical filtration volume," the porous cellulose membrane achieved complete rejection of viruses from the filtrate.

4) The critical filtration volume depends on filtration pressure and virus concentration in filtrand: the accumulation was considered to occur frequently at higher pressure and with higher concentration of virus in the filtrand; the blocking tended to occur easily at lower $c_{0}$.

\section{REFERENCES}

1. K. Kamide and S. Manabe, in "Material Science of Synthetic Membranes, ACS Symposium Series, No. 269, D. R. Lloyd, Ed., American Chemical Society, Washington, D.C., 1985, pp $197-228$.

2. S. Manabe, Y. Kamata, H. Iijima, and K. Kamide, Polym. J., 19, 391 (1987).

3. S. Manabe, H. Iijima, and K. Kamide, Polym. J., 20, 307 (1988).

4. K. Kamide, "Thermodynamics of Polymer Solutions," A. D. Jenkins, Ed., Elsevier Science Publisher B. V., Amsterdam, The Netherlands, 1990, p 548.

5. K. Kamide, H. Iijima, and S. Matsuda, Polym. J., 25, 1113 (1993).

6. K. Kamide, H. Iijima, and H. Shirataki, Polym. J., 26, 21 (1994).

7. H. Iijima, S. Matsuda, and K. Kamide, Polym. J., 26, 439 (1994).

8. K. Kamide, H. Iijima, and A. Kataoka, Polym. J., 26, 623 (1994).
9. H. Iijima, A. Kataoka, and K. Kamide, Polym. J., 27, 1033 (1995).

10. W. J. Elford, J. Path. Bact., 34, 505 (1931).

11. J. D. Ferry, Chemical Reviews, 18, 373 (1936).

12. For example, T. Miyake, T. Shiba, and I. Watanabe, Jpn. J. Microbiol., 11, 203 (1967); M. Trudel and P. Payment, Can. J. Microbiol., 26, 1334 (1980); K. Hou, C. P. Gerba, S. M. Goyal, and K. S. Zerda, Applied and Environmental Microbiology, 40, 892 (1980); J. Steinmann, ibid., 41, 1043 (1981); S. Farrah, ibid., 43, 659 (1982); S. N. Singh and C. P. Gerba, ibid., 45, 232 (1983); D. M. Dziewulski and G. Belfort, Wat. Sci. Tech., 15, 75 (1983); R. N. Purdy, B. N. Dancer, M. J. Day, and D. J. Stickler, J. Applied Bacteriology, 58, 231 (1985).

13. See, for example, C. Wallis and J. Melnick, J. Virology, 1, 472 (1967); B. A. Ver, J. L. Melnick, and C. Wallis, Virology, 2, 21 (1968).

14. Y. Hamamoto, S. Harada, S. Kobayashi, K. Yamaguchi, H Iijima, S. Manabe, T. Tsurumi, H. Aizawa, and N. Yamanoto, Vox Sang., 56, 230 (1989).

15. T. Tsurumi, N. Osawa, T. Hirasaki, K. Yamaguchi, S. Manabe, and T. Yamashiki, Polym. J., 22, 304 (1990).

16. T. Tsurumi, N. Osawa, H. Hitaka, T. Hirasaki, K. Yamaguchi, S. Manabe, and T. Yamashiki, Polym. J., 22, 751 (1990).

17. Japanese Patent Application, 58-89625 (1983).

18. Japanese Patent Application, 59-204911 (1984)

19. "Polymer Handbook, 3rd ed," J. Brandrup and E. H. Immergut, Ed., John Wiley \& Sons, Inc., New York, N.Y., 1989, p V/122.

20. See, for example, R. E. Kesting, "Synthetic Polymer Membranes," 2nd ed, John Wiley \& Sons, Inc., New York, N.Y.,1985, p 49 .

21. "The Microbial World 5th ed," R. Y. Stanier, J. L. Ingraham, M. L. Wheelin, and P. R. Painter, Ed., Prentice-Hall, Englewood Cliffs, N. J., 1986, p 217.

22. "A Picture Book of Virus," Y. Hosaka, S. Kawase, and T. Matsui, Ed., Kodansha, Tokyo, Japan, 1972, p 610.

23. B. Alberts, D. Bray, J. Lewis, M. Raff, K. Roberts, and J. D. Watson, "Molecular Biology of the Cell," Garland Publishing, Inc., New York, N.Y., 1983, p 233.

24. See, for example, H. Fraenkel-Conrat and P. C. Kimball, "Virology," Prentice-Hall, Inc., Englewood Cliffs, N. J., 1982.

25. See, for example, M. Essex and P. J. Kanki, Scienctific American, October 1988, p 44

26. K. Kamide and H. Iijima, in "Cellulosic Polymers, Blends and Composites," R. D. Gilbert, Ed., Carl Hanser Verlag, New York, N.Y., 1994, p 189. 